Altai State University

www.asu.ru

ISSN 2412-1908

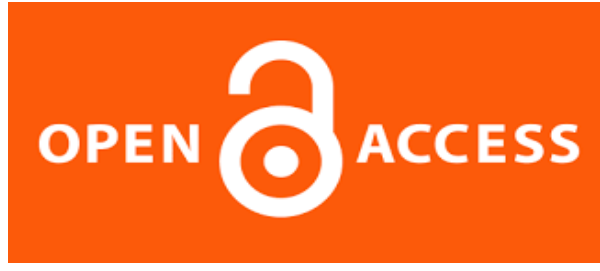

Acta Biologica Sibirica, 2018, 4(1), 33-37

\title{
The initial stage of the study of spiders (Aranei) in Grabove ravine (Piatikhatkyi district, Dnepropetrovsk region)
}

\author{
E.V. Prokopenko' ${ }^{1}$ A.V. Zhukov ${ }^{2}$ \\ ${ }^{1}$ Donetsk National University, Shchorsa Str. 46, Donetsk 83112 Ukraine, \\ E-mail: helen_procop@mail.ru \\ 2 Oles Gonchar Dnipro National University, Gagarina Av. 72, Dnipro 49010 Ukraine, \\ E-mail: zhukovdnepr@rambler.ru
}

\begin{abstract}
Linden-hornbeam oak forests in Grabove ravine can be regarded as the easternmost outpost of the massive distribution of the hornbeam in Ukraine. The material for this paper was collected in Belenschina Village (Piatikhatskyi District, Dnepropetrovsk Region) since May to June 2009 using pitfall traps. Glass jars of 0,5 liter volume containing $2 \%$ formalin served as pitfall traps. There are 524 trap-days were spent and 402 specimens were collected. A total 18 spider species from 9 families are recorded. This result does not reflect the actual species richness in Grabove ravine. There is a need to take further research to complete the spider species list. Maximal species richness and abundance characterize families Lycosidae (5 species, 84,1 \% specimens) and Thomisidae (3 species, 7,3\% specimens). The largest number of spider species was recorded in the lower third of the southern slope (11 species), the largest value of dynamic density was in the middle third of the southern slope (154,4 specimens/100 trap-days). The minimal species richness (5 species) was found in the middle third of the northern slope. The lowest values of dynamic density were recorded in the lower third of the northern slope (39,4 specimens/100 trap-days).
\end{abstract}

Key words: spiders, Aranei, fauna, steppe ravine

\section{Начальный этап изучения пауков (Aranei) урочища Грабовое (Пятихатский район Днепропетровской области)}

\author{
Е.В. Прокопенко ${ }^{1}$, А.В. Жуков ${ }^{2}$ \\ ${ }^{1}$ Донецкий национальный университет, ул. Щорса 46, Донецк 83112 украина, \\ E-mail: helen_procop@mail.ru \\ ${ }^{2}$ Днепропетровский национальный университет им. Олеся Гончара, \\ nр. Гагарина 72, Днепр 49010 Украина, E-mail: zhukov dnepr@rambler.ru
}

\footnotetext{
В урочище Грабовое (с. Беленщина, Пятихатский район, Днепропетровская область) отмечено 18 видов пауков, относящихся к 9 семействам. Наибольшим видовым богатством и относительной численностью характеризуются семейства Lycosidae (5 видов, 84,1 \% общего обилия) и Thomisidae (3 вида, 7,3 \%). Наибольшее количество видов пауков отмечено в нижней трети склона южной экспозиции (11 видов), наибольшее значение динамической
} 
плотности - в средней трети склона южной экспозиции (154,4 экземпляра на 100 ловушко-суток). В средней трети северного склона найдено наименьшее количество видов пауков (5 видов). Наиболее низкие значения динамической плотности зарегистрированы в нижней трети склона северной экспозиции (39,4 экземпляров на 100 ловушко-суток).

Ключевые слова: пауки, Aranei, фауна, степная балка

\section{Введение}

Байрачные, или балочные леса произрастают по склонам и днищам балок в полосе разнотравно-типчаковоковыльных степей (этот регион иногда называют байрачной степью) и считаются эталонами лесных условий в степной зоне (Gilyarov, 1953). Разнообразие экотопов, пестрота растительного покрова и связанного с ним животного населения являются характерной чертой байрачных лесов.

Ранее нами был собран и проанализирован материал по паукам степных балок в пределах Днепропетровской, Донецкой и Херсонской областей (Zhukov et al., 2008; Kunakh et al., 2008; Prokopenko, 2003; Prokopenko, Zhukov, 2009, 2011, 2018; Prokopenko et al., 2009, 2010). В настоящей работе рассматриваются сообщества пауков наземного яруса байрачного леса на северо-западе Днепропетровской области.

\section{Материал и методы исследований}

Липово-грабовые дубравы в урочище Грабовое (с. Беленщина, Пятихатский район, 4845'25" N 3349'47" E) можно расценивать как самый восточный форпост сплошного распространения этой древесной породы на территории Украины (Belgard, 1971).

Материал собирался непрерывно с 5.05 по 5.06.09 г. с помощью почвенных ловушек (0,5 л. стеклянные банки с раствором 2 \% формалина) в следующих биотопах: 1) верхняя треть склона южной экспозиции, липово-ясеневая дубрава с ежой (4845'23.33" N 3351'20.82" Е) (ВЮ); 2) средняя треть склона южной экспозиции, липово-грабовая дубрава со звездчаткой (4845'20.28" N 3351'17.94" Е) (СЮ); 3) нижняя треть склона южной экспозиции, липовограбовая дубрава со звездчаткой (4845'17.32" N 3351'12.85" Е) (НЮ); 4) тальвег, липово-грабовая дубрава со снытью (4845'15.75" N 3351'5.52" Е) (Т); 5) нижняя треть склона северной экспозиции, липово-грабовая дубрава с широкотравьем (4845'13.52" N 3351'1.27" Е) (НС); 6) средняя треть склона северной экспозиции, липово-грабовая дубрава с широкотравьем (4845'12.84" N 3350'55.15" Е) (СС); 7) верхняя треть склона северной экспозиции, липово-грабовая дубрава с широкотравьем (4845'13.61" N 3350'44.36" Е) (ВС). Ловушки были размещены на трансекте в поперечном сечении северного ответвления балки. Разница высот между местами установки ловушек в верхней трети склона южной экспозиции и тальвегом составила 23 м, верхней трети склона северной экспозиции и тальвегом - 24 м. В каждом биотопе выставляли по 3 ловушки, которые располагались на вершинах равностороннего треугольника с длиной ребра 3 м (Pontegnie, 2005). Материал из трех ловушек в каждом биотопе объединяли в одну пробу. Выемка животных из ловушек производилась три раза за указанный период.

Всего отработано 524 ловушко-суток, собрано 402 экземпляра пауков. Количество ловушко-суток (524) меньше запланированного (651) т.к. в отдельные периоды некоторые ловушки были нарушены (засыпаны землей, выброшены и т.д.). Динамическая плотность пауков приведена в количестве экземпляров, собранных за 100 ловушко-суток (экз./100 лов.-сут.). Относительную численность видов оценивали по простой порядковой шкале (Dufrene, Legendre, 1997): 1 класс - 0-2\%, 2 класс - 2-5\%, 3 класс - 5-10\%, 4 класс - 10-20\%, 5 класс - 20-100\% собранных экземпляров. Статистическую обработку проводили в программе Past (Hammer et al., 2001).

\section{Результаты и обсуждение}

Известно, что различия микроклиматических условий делают степную балку сложным комплексом местообитаний. Тальвег характеризуется большим увлажнением, меньшей скоростью ветра и сглаженным сезонным и суточным ходом температур. Значительно отличаются условия и на склонах различной экспозиции: наиболее теплообеспеченные склоны - южные, затем идут западные, восточные и северные. Причем склоны южной экспозиции тем теплее, чем они круче, северной же, наоборот, холоднее (Belgard, 1971). Эти особенности отражаются на составе растительности и животного населения, типе почвообразовательного процесса, которые закономерно изменяются по профилю степной балки - от верхних частей склонов, граничащих с плакором, до аккумулятивной позиции в тальвежной части. Было показано, что наибольшие отличия от зонального типа прослеживаются в тальвегах балок, имеющих местами луговой характер и включающих отдельные лесные виды. С другой стороны, с южными склонами связаны даже более ксерофильные группировки, чем в зональных степных сообществах плакора (Arnoldi, 1956). Описанные особенности микроклиматических условий наложили отпечаток на состав и структуру населения пауков исследованных местообитаний.

В результате проведенных исследований в урочище Грабовое отмечено 18 видов пауков из 9 семейств (табл. 1). Полученный результат не отражает в полной мере видовое богатство аранеофауны данного локалитета, и можно предположить, что последующие сборы материала значительно расширят видовой список. 
Prokopenko, E.V., Zhukov, A.V. The initial stage of the study of.... Acta Biologica Sibirica, 2018, 4(1), 33-37

Таблица 1. Видовой состав и класс численности пауков исследованных биотопов

Вид

Harpactea rubicunda (C. L. Koch, 1838)

Abacoproeces saltuum (L. Koch, 1872)

Panamomops mengei Simon, 1926

Pachygnatha listeri Sundevall, 1830

Arctosa lutetiana (Simon, 1876)

Pardosa agrestis (Westring, 1861)

Pardosa alacris (C. L. Koch, 1833)

Piratula hygrophila (Thorell, 1872)

Trochosa terricola Thorell, 1856

Pisaura novicia (L. Koch, 1878)

Mastigusa arietina (Thorell, 1871)

Agroeca brunnea (Blackwall, 1833)

Haplodrassus silvestris (Blackwall, 1833)

Zelotes fuscus (Thorell, 1875)

Zora spinimana (Sundevall, 1833)

Ozyptila praticola (C. L. Koch, 1837)

Xysticus Ianio C. L. Koch, 1835

Xysticus luctator L. Koch, 1870

Динамическая плотность

\begin{tabular}{|c|c|c|c|c|c|c|}
\hline \multicolumn{7}{|c|}{ Биотопы } \\
\hline ВЮ & СЮ & НЮ & $\mathrm{T}$ & $\mathrm{HC}$ & $\mathrm{CC}$ & $B C$ \\
\hline 3 & - & 2 & - & - & - & - \\
\hline- & - & - & - & 2 & 1 & 2 \\
\hline- & - & 1 & - & - & - & - \\
\hline- & - & - & 1 & 3 & - & - \\
\hline 2 & 3 & 4 & - & - & - & 2 \\
\hline 1 & - & - & - & - & - & - \\
\hline 5 & 5 & 5 & 4 & 5 & 5 & 5 \\
\hline- & - & - & 5 & 2 & - & - \\
\hline 2 & 2 & 3 & 4 & 4 & 4 & 4 \\
\hline- & - & 3 & 1 & - & - & 2 \\
\hline- & - & 1 & - & - & - & - \\
\hline 1 & 1 & 1 & 1 & - & - & 2 \\
\hline 3 & - & - & - & - & 2 & - \\
\hline- & - & 1 & - & - & - & - \\
\hline- & - & - & - & 2 & - & 2 \\
\hline- & 3 & 4 & 1 & 4 & 2 & - \\
\hline- & - & - & 1 & - & - & - \\
\hline - & 2 & 2 & - & - & - & 2 \\
\hline 57,0 & 154,4 & 73,0 & 93,5 & 39,4 & 88,2 & 48,4 \\
\hline
\end{tabular}

Примечание: обозначения биотопов приведены в разделе «Материалы и методы»

Наибольшим видовым богатством и относительной численностью характеризуются семейства Lyсоsidae (5 видов, 84,1 \% общего обилия) и Thomisidae (3 вида, 7,3 \%). Единственным видом представлено 6 семейств. Матрица «класс численности - биотопическое распределение» (табл. 1) содержит 60 \% нулевых значений, что отражает значительную степень рассредоточенности видов по позициям байрачной катены: 58 \% видов найдены в 1-2 местообитаниях и только $P$. alacris и T. terricola отмечены повсеместно.

Количество видов пауков изменяется от 5 на середине склона северной экспозиции до 11 - в нижней трети склона южной экспозиции. В тальвеге балки собрано 8 видов. Динамическая плотность пауков варьирует в широких пределах от 39,4 экз./100 лов.-сут. в нижней трети склона северной экспозиции до 154,4 экз./100 лов.-сут. на середине склона южной экспозиции (табл. 1). В тальвеге этот показатель составил 93,5 экз./100 лов.-сут.

Виды T. terricola и P. alacris отмечены во всех исследованных биотопах. T. terricola, в степной зоне Левобережной Украины регистрировавшийся в широком спектре биотопов (Polchaninova, Prokopenko, 2013, 2017), наиболее обилен в тальвеге и на позициях северного склона, достигая в этих местообитаниях 4 класса численности (табл. 1). P. alacris приурочен в степной зоне в основном к лесным ценозам, изредка встречаясь в луговых и опушечных местообитаниях (Polchaninova, Prokopenko, 2013, 2017). Этот вид во всех исследованных биотопах имеет наивысший 5 класс численности, кроме тальвега, где этот показатель снижается до 4 класса.

Интересна находка редкого в Левобережной Украине вида семейства Hahniidae - Mastigusa arietina, известного в Новгород-Северском Полесье (Черниговская, Сумская области) (Evtushenko, 1993) и в заповеднике «Каменные Могилы» (Донецкая область) (Polchaninova, Prokopenko, 2013, 2017).

Только в тальвеге и на нижних третях склонов северной и южной экспозиции отмечены $P$. hygrophila, P. listeri, X. lanio, P. mengei, M. arietina, Z. fuscus. Это виды, встречающиеся в степной зоне преимущественно в лесных и увлажненных травянистых местообитаниях. P. hygrophila, предпочитающий околоводные биотопы, единственный из отмеченных в тальвеге видов, имеет 5 класс численности.

Наиболее сухими и теплыми являются верхняя и средняя трети склона южной экспозиции - только здесь пойман P. agrestis. Этот вид типичен для степных и луговых биотопов, только изредка встречаясь под древесным пологом (Polchaninova, Prokopenko, 2013, 2017).

Уровень общности структуры сообществ пауков исследованных биотопов оценивался с помощью индекса Морисита (Hammer, 1999-2018). Сообщества пауков на склонах балки характеризуются значительным сходством (табл. 2, рис. 1). Наибольшее сходство демонстрируют сообщества средних третей склонов южной и северной экспозиции и верхней трети склона южной экспозиции. 
Prokopenko, E.V., Zhukov, A.V. The initial stage of the study of.... Acta Biologica Sibirica, 2018, 4(1), 33-37

Таблица 2. Значения индекса Морисита для сообществ пауков исследованных биотопов

\begin{tabular}{llllllll}
\hline & $\mathrm{B}$ & $\mathrm{C}$ & $\mathrm{H}$ & $\mathrm{T}$ & $\mathrm{HC}$ & $\mathrm{CC}$ & $\mathrm{BC}$ \\
$\mathrm{B}$ & 1 & 0,99 & 0,87 & 0,29 & 0,82 & 0,99 & 0,95 \\
$\mathrm{C}$ & 0,99 & 1 & 0,88 & 0,29 & 0,83 & 0,99 & 0,94 \\
$\mathrm{H}$ & 0,87 & 0,88 & 1 & 0,29 & 0,92 & 0,87 & 0,92 \\
$\mathrm{~T}$ & 0,29 & 0,29 & 0,29 & 1 & 0,38 & 0,30 & 0,32 \\
$\mathrm{HC}$ & 0,82 & 0,83 & 0,92 & 0,38 & 1 & 0,86 & 0,91 \\
$\mathrm{CC}$ & 0,99 & 0,99 & 0,87 & 0,30 & 0,86 & 1 & 0,96 \\
$\mathrm{BC}$ & 0,95 & 0,94 & 0,92 & 0,32 & 0,91 & 0,96 & 1 \\
\hline
\end{tabular}

Примечание: обозначения биотопов приведены в разделе «Материалы и методы»

Сообщество пауков тальвега балки отличается наибольшей специфичностью по отношению к сообществам склоновых местообитаний. Причем наибольшее сходство сообщество тальвега имеет с сообществом нижней трети северного склона.

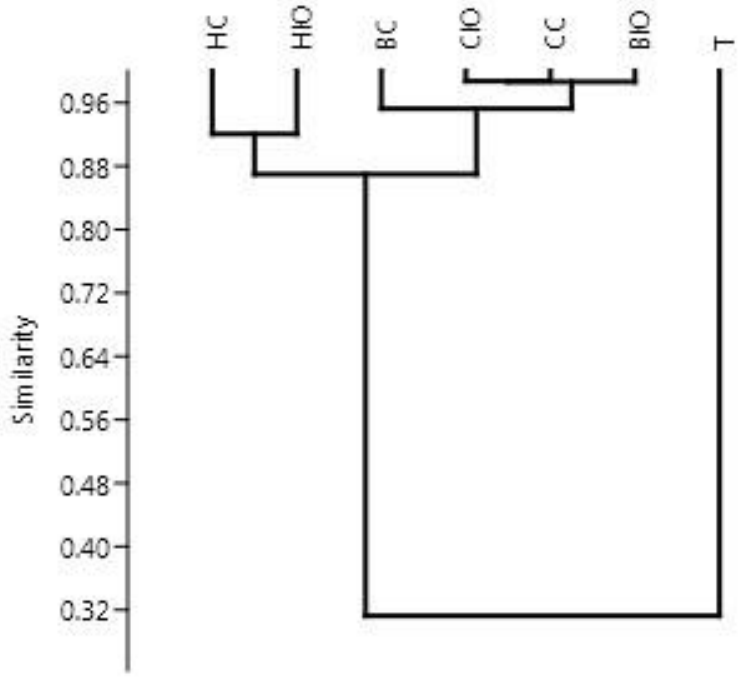

Рис. 1. Дендрограмма сходства структуры сообществ пауков исследованных биотопов (индекс Морисита, UPGMA)

\section{Выводы}

Таким образом, в урочище Грабовое отмечено 18 видов пауков из 9 семейств. Наибольшим видовым богатством и относительной численностью характеризуются семейства Lycosidae и Thomisidae (5 видов, 84,1\% общего обилия и 3 вида, 7,3\% общего обилия, соответственно). Наибольшее количество видов пауков отмечено в нижней трети склона южной экспозиции (11 видов), наибольшее значение динамической плотности - в средней трети склона южной экспозиции (154,4 эк3. на 100 лов.сут.). В средней трети северного склона найдено наименьшее количество видов пауков (5 видов). Наиболее низкие значения динамической плотности зарегистрированы в нижней трети склона северной экспозиции (39,4 экз. на 100 лов.-сут.). Сообщество пауков тальвега демонстрирует значительную специфичность в сравнении с сообществами склонов степной балки.

\section{References}

Arnoldi, K. V. (1956). An outline of entomofauna and characteristics of entomocomplexes of forest litter in the region of Derkul. Trudy Instituta lesa, 30, 279-342 (in Russian).

Belgard, A. L. (1971). Steppe forestry. M.: Lesnaya promyshlennost (in Russian).

Dufrene, M. Legendre, P. (1997). Species assemblages and indicator species: the need for a flexible asymmetrical approach. Ecological Monographhs, 67(3), 345-366. doi: 10.1890/0012-9615(1997)067[0345:SAAIST]2.0.CO;2

Evtushenko, K. V. (1993). [To the study of spiders (Aranei) of the Novgorod-Severskoe Polesye.]. Red. zh. Vestnik Zoologii. Kiev. Dep. VINITI 06.01.93. No.26-B93. (in Russian).

Gilyarov, M. S. (1953). Soil fauna of bairak forests and its significance for soil diagnostics. Zoologicheskiy zhurnal, 32(3), 328-347.

Hammer, Ø. PAST. (1999-2018). Paleontological statistics. Version 3.19. Reference manual, 259. Available from: https://folk.uio.no/ohammer/past/past3manual.pdf. Accessed 13 March 2018.

Hammer, Ø., Harper, D. A. T., Ryan P. D. (2001). PAST: Paleontological statistics software package for education and data analysis. Palaeontologia Electronica, 4(1), 9.

Kunakh, O. N., Zhukov, A. V., Prokopenko, E. V., \& Balyk, Yu. A. (2008). Ecological structure of the animal population of the Yatsev Yar Ravine. Bulletin of Dnepropetrovsk University. Biology. Ecology, 16(2), 74-85 (in Russian).

Polchaninova, N. Yu., \& Prokopenko, E. V. (2013). Catalogue of the spiders (Arachnida, Aranei) of Left-Bank Ukraine. Arthropoda Selecta, Supplement No.2. M.: KMK Scientific Press Ltd., 1-268.

Polchaninova, N. Yu., \& Prokopenko, E. V. (2017). Catalogue of the spiders (Arachnida, Aranei) of Left-Bank Ukraine. Addendum 1. 2013 - 2016. Arthropoda Selecta, Supplement No.4. M.: KMK Scientific Press Ltd., 1-115. 
Prokopenko, E.V., Zhukov, A.V. The initial stage of the study of.... Acta Biologica Sibirica, 2018, 4(1), 33-37

Pontegnie, M., du Bus de Warnaffe, G., Lebruna, Ph. (2005). Impacts of silvicultural practices on the structure of hemiedaphic macrofauna community. Pedobiologia, 49, 199-210. doi.org/10.1016/j.pedobi.2004.09.005

Prokopenko, E. V. (2003). Population structure of spiders (Aranei) of the tree plantations in Donetsk. Vestnik zoologii, Supplement 16, 108-110 (in Russian).

Prokopenko, O. V., Kunakh, O. M., Zhukov, O. V., \& Pakhomov, O. E. (2010). Biological diversity of Ukraine. Dnipropetrovsk region. Spiders (Aranei). Dnipropetrovsk: Izdatelstvo of Dnipropetrovsk National University (in Ukrainian).

Prokopenko, E. V., Pakhomov, A. E. Kunakh, O. N., \& Zhukov, A. V. (2009). Ecological structure of the spider community (Araneae) in Voiskovaya Ravine Bulletin of Dnepropetrovsk University. Biology. Ecology, 1(17), 183-192 (in Russian).

Prokopenko, E. V., \& Zhukov, A. V. (2009). Structure of spider population (Araneae) of the bairak forests of Dnipropetrovsk Region. Problems of ecology and nature protection of the technogenic region. Donetsk: DonNU, 9, 124-130 (in Russian).

Prokopenko, E. V., \& Zhukov, A. V. (2011). The population structure of spiders (Aranei) of the bayrak katena. Bulletin of Donetsk University. Ser. A. Natural sciences, 2, 145-150 (in Russian).

Prokopenko, E. V., \& Zhukov, A. V. (2018). Spider (Aranei) steppe community in a ravine with fescue-feather-grass petrophytic vegetation. Acta Biologica Sibirica, 4(1), 17-21 (in Russian).

Zhukov, A. V., Kunakh, O. N., Prokopenko, E. V., \& Balyk, Yu. A. (2008). Ecological diversity and organization of the animal population of Yatsev Yar Ravine. Bulletin of Dnepropetrovsk University. Biology. Ecology, 16(2), 51-59 (in Russian).

\section{Citation:}

Prokopenko, E.V., Zhukov, A.V. (2018). The initial stage of the study of spiders (Aranei) in Grabove ravine (Piatikhatkyi district, Dnepropetrovsk region). Acta Biologica Sibirica, 4 (1), 33-37.

Submitted: 12.12.2017. Accepted: 20.02.2018

crossref http://dx.doi.org/10.14258/abs.v4i1.3914

(C) 2018 by the authors. Submitted for possible open access publication under the terms and conditions of the Creative Commons Attribution (CC BY) license (http://creativecommons.org/licenses/by/4.0/). 